\title{
African American Student Persistence at a Predominantly White Institution
}

\author{
Brian Bourke and Nathaniel J. Bray
}

Persistence in college among African American students continues to remain low compared to persistence among White students. Often, the focus in examining this issue has been on institution-wide retention efforts, which can ignore socio-cultural elements that can influence the decisions of individual students to persist at an institution; however, persistence may rely on a combination of institutional factors and socio-cultural elements. The purpose of this article is to present findings from a research project that highlight institutional factors and socio-cultural elements that influence the persistence of African American students at a predominantly White institution. The findings from focus groups with African American students suggest that they persist despite a "cold" campus climate and ongoing experiences with racism and prejudice at Southern State University [pseudonym].

The retention and persistence of African Americans in higher education are issues that have received increased attention in scholarly literature in recent years and remain of continued importance and urgency (Holmes, Ebbers, Robinson, \& Mugenda, 2000; Tierney, 2000). African American students continue to lag behind White students in persisting to graduation, at $40 \%$ compared to $60 \%$, respectively, for students who graduate from an institution within six years of entering (Strayhorn, 2008). This problem is particularly alarming as African American students continue to remain underrepresented in higher education, which, in turn, affects the representation of African Americans in the workplace, notably in professional fields (Smith \& Wolf-Wendel, 2005). For these reasons, examining elements that support or preclude persistence of African American students is of compelling interest to higher education. There are significant implications that arise from looking at the persistence of African American students in a predominantly White institution (PWI) (Swail, Redd, \& Perna, 2003).

The experiences of African American undergraduates attending a PWI and the connections of those experiences to college student persistence are the focus of this research. While the researchers discuss institutional retention efforts, it is with a focus on their impact on the students and their decision making about persisting. Although research examining persistence of students of color has increased in recent years, the theories of student persistence and departure that are most often

Brian Bourke (bbourke@lsu.edu) is an Assistant Professor in Higher Education \& Student Affairs at the Louisiana State University.

Nathaniel J. Bray (nbray@bamaed.ua.edu) is an Associate Professor in Higher Education at The University of Alabama. 
cited are based on a homogenous view of college students, which is grounded in Whiteness (Rendón, Jalomo, \& Nora, 2000). As this study will demonstrate, students who participated in this study persisted due to their own desires and efforts, and not as a result of efforts made by the institution to retain African American students. The focus of this study is on the experiences of students and factors that contribute to their persistence at an institution that they feel is chilly and unwelcoming.

\section{Review of Relevant Literature}

The most widely cited literature pertaining to student retention and persistence continues to draw on Spady (1971) and Tinto $(1975,1987,1993)$. Tinto's $(1975,1993)$ interactionalist model of student departure is one of the most readily recognized and well known in the field of higher education; Braxton, Sullivan, and Johnson (1997) noted Tinto's interactionalist model has reached near paradigmatic status; however, the shortcomings of these works for their inapplicability to students of color have been articulated by multiple scholars (Braxton, 2000; Braxton, Hirschy, \& MClendon, 2004; Guiffrida, 2006; Tierney, 1992; Tierney, 2000). Much of this inapplicability to the experiences of students of color comes from the basis of the widely cited works in concepts of assimilation.

Extant literature suggests that "Astin's (1984) concept of 'involvement' and Tinto's $(1975,1993)$ definition of 'integration' are the conceptual underpinnings" of understanding persistence, and as such, involvement and social integration need to be considered in both retention and persistence studies (Berger \& Milem, 1999, p. 641). Part of the problem with Tinto's $(1975,1993)$ work, and with some of the attempts at theory elaboration upon it, is that many of these studies do not adequately address the various ways different student populations are integrated or impacted by integration in other social groups external to campus (Guiffrida, 2006; Tierney, 2000). A number of authors have identified elements of PWIs that might preclude success among African American students, as well as students from other underrepresented groups (Harper \& Quaye, 2007; Lewis, Chesler, \& Forman, 2000; Loo \& Rolison, 1986; Nora \& Cabrera, 1996). Cabrera, Nora, Terenzini, Pascarella, and Hagedorn (1999) contended that perceptions of the campus climate by African American students can have a significant impact on adjustment to the institution.

Levin, Van Laar, and Foote (2006) found that as African American students perceived greater levels of discrimination on campus, they became more academically motivated; however, this should not be taken as a shining beacon of hope. In order for this level of reaction to be realized, African American students need to benefit from a peer-support network on campus (Person \& Christensen, 1996). It has been postulated that African American students who react to perceptions of and experiences with discrimination and racism on campus by becoming more motivated to perform at a higher level might have also progressed further along developmental lines (Flowers, 2004). This does not mean that hostile and unwelcoming campus environments are ultimately beneficial to African American students. 
The environment of PWIs is a central element of the literature and is critical to student persistence and success. Harper and Quaye (2007) wrote about the importance of White student stakeholders creating spaces for African American students and students from other underrepresented populations to be engaged in campus programming decisions and dialogue. They suggested that institutions cannot take for granted that African American students have reached these higher levels of development and, therefore, will be more likely to feel spurred on by discrimination and racism on campus. Indeed, Museus and Quaye (2009) argued that cultural dissonance has an opposite effect on minority student persistence; those students who come to college from predominantly White high schools or cultural backgrounds are more likely to succeed at a PWI that has not followed Harper and Quaye's suggestion above.

\section{Conceptual Framework}

The likelihood of persistence increases as a student feels connected to the social environment of the institution (Braxton et al., 2004; Tinto, 1975). An important component of social integration is student-institution fit (Cabrera, Castaneda, Nora, \& Hengstler, 1992; Swail, Redd, \& Perna, 2003). Studentinstitution fit means that a student finds congruence between who the student is and various elements of the institution, from the social environment, to the classroom, to expectations that students feel from external forces.

Braxton et al. (2004) worked to provide a revision of Tinto's interactionalist theory of student departure. In doing so, the authors sought to remedy elements of Tinto's $(1975,1993)$ theory that neglect the experiences of African American students, particularly the relationship between integration and assimilation into the dominant culture proposed within the framework of Tinto's (1975) work. Persistence is dependent on student's level of social integration, and integration, in turn, is reliant on six empirically grounded propositions proposed by Braxton et al. (2004). These six propositions state students' level of social integration is enhanced in the following ways:

1. A student's perception that the institution is committed to the welfare of its students;

2. A student's perception of the potential of community on campus;

3. A student's perception that the institution exhibits institutional integrity;

4. The student's use of proactive social adjustment strategies;

5. The amount of psychological energy students invest in various social interactions at their college or university;

6. The students' level of satisfaction with the costs of attending their chosen institution (Braxton et al., 2004, pp. 23-28).

Student integration is linked to student involvement, particularly in the form of involvement with peers. Pascarella and Terenzini $(1991 ; 2005)$ suggested that among other factors, educational aspirations and educational attainment can be influenced by involvement with peers. Braxton et al. (2004) included propositions 
pertaining to student characteristics upon entering the institution that can impact students' integration into the institution; however, for the purposes of this study, the propositions that address social integration are being examined.

\section{Method}

The research design and data collection methods can be described as qualitative. Qualitative methods were chosen due to their suitability in exploring and attempting to understand the intricacies of individual experience, as the focus of this study is on the individual experience of African American student persistence. To conduct this project, a single institution was chosen as the site of study.

Focus groups represent a unique form of data collection. The variability of background, experiences, and personality across participants, even in a homogenous group, can yield a space in which a dynamic group interaction can occur (Stewart, Shamdasani, \& Rook, 2007). While focus group data may not provide the depth of individual interviews, focus groups do offer multiple benefits. Focus groups can be beneficial as a form of data collection in qualitative research as they can offer insights into how groups construct meaning (Bloor, Frankland, Thomas, \& Robson, 2001). Through the interactions between participants, additional lines of inquiry might emerge that may not occur through individual interviews, as the group dynamic produced the space that steers the discussion in a new direction (Morgan, 1997). For example, during a focus group, one participant may offer a comment that sparks a thought in another participant who shares a reaction to the first participant's statement.

\section{Site Context}

Southern State University enrolls approximately 22,000 students and the percentage of students who live in on-campus residences falls within the 25-49\% range, which is the basis for residential classification by the Carnegie Foundation for institutions of this size (Carnegie Foundation, 2010). Situated in the southern United States, Southern State University reflects the conservative nature of its home and neighboring states. Its history of integration is recent, and the institution still struggles with issues of diversity and inclusion. These recent struggles include repeated vandalism of facilities housing minority-based student organizations and the performance of blackface by White students. Specific details about these struggles are not provided to maintain confidentiality of Southern State University. Institutional anonymity was a condition of access and was included documentation filed with the Institutional Review Board. Institutional anonymity was also communicated to study participants as a means to further maintain the confidentiality of each focus group. 


\section{Data Collection and Analysis}

Data were collected through five focus groups providing a total of 40 African American undergraduate students, with each focus group ranging in size between eight and thirteen students. Student affairs staff provided assistance in recruiting participants. A script was provided by the researchers to aid the student affairs staff in participant recruitment. Each focus group was facilitated by the first author of this article using a semi-structured protocol. The focus group protocol included questions that focused on students' social experiences on campus. These questions were asked in an effort to best understand students' social integration. Each focus group was planned to last one hour, but each of the five exceeded that time, with one lasting nearly two hours.

The focus groups were audio recorded, and those recordings were transcribed. Those transcripts were coded using an open coding (Strauss \& Corbin, 1998) approach, with each author coding the transcripts independently. From a comparison of the independent code lists, a unified coding schema was created, which was then used in conjunction with the Braxton et al. (2004) propositions. Through this analysis, the researchers identified segments of the coded data that serve as commentary to each of the propositions, providing varying levels of support for each. The results of this analysis are shared in the Findings and Discussion section.

Focus Group Protocol. The focus group protocol is provided to offer the reader a sense of the content of the focus groups. These seemingly generic questions were used to facilitate conversations with the participants. The broad topics proved useful in helping participants open up about their experiences at Southern State University. Questions specific to issues of race were based in existing literature addressing the experiences of African American students attending PWIs.

1. What is life like at Southern State University?

2. Tell me about a typical Friday night.

3. Who do you talk to for advice at Southern State University?

4. Who do you socialize with?

a. Do those people change based on the setting on campus?

5. Are you active in any organizations or activities on campus?

a. What does your activity entail?

6. Is Southern State University welcoming to you as a member of a minority group?

7. Do you feel at home at Southern State University?

8. Do you ever feel that you are an outsider here?

a. If so, what brings those feelings out?

9. Do you feel that you have to prove yourself here due to your race or ethnicity?

a. If so, how do you go about doing that? 
In qualitative research, the identity and biases of each researcher has the potential to influence the research, from data design, to data collection, to data analysis. Both authors of this article are White men who attended PWIs and are faculty members at PWIs. The first author listed on this article conducted the focus groups for this research. Being mindful of these biases cannot eliminate their influence in the research, but this mindfulness can aid in mitigating the influence of biases. With that being said, the researchers' past experiences do come into play throughout the research process.

\section{Findings and Discussion}

The findings from the current study are presented in their relationships to the propositions regarding persistence among students of color in residential institutions offered by Braxton et al. (2004):

1. institutional commitment to student welfare,

2. student perceptions of potential campus community,

3. student use of proactive social adjustment strategies,

4. student investment in social interactions,

5. student perceptions of institutional integrity, and

6 . student satisfaction with the cost of attendance.

As the propositions are not defined by Braxton et al. (2004), or by Braxton et al. (1997), the findings relayed here attempt to provide an introduction into how these social integration elements look and affect African American student persistence. The findings also support the literature that suggests the critical nature of environment on African American student persistence at PWIs. Student satisfaction with the cost of attendance was not addressed by participants. All participants are represented by pseudonyms as a means to protect anonymity.

\section{Institutional Commitment to Student Welfare}

African American students in this study did not perceive the institution to be strongly committed to the welfare of its African American students and other students of color, as they perceived and experienced discrimination and other forms of racism. Students of color do not see themselves represented in formal involvement opportunities at Southern State University beyond either African American fraternities or sororities or in student organizations that are focused on the experiences of students of color. In several other main facets of campus life that involve student structured discourse, such as honor societies, student government, and other coordinating councils, the dominance of Whiteness is clearly evident.

Similar to the findings of Levin et al. (2006), African American participants of the current study responded to perceptions of and experiences with discrimination 
at Southern State University by feeling motivated to succeed. They expressed being spurred on to prove those who would discriminate against them wrong. Christina, an African American second-year student, had the following to say about the nature of double standards and their basis in stereotypes:

The stereotypes against us are completely different than the ones against [White students]. If they [White people] act a fool, that's just one stupid person. But if an African American person does something, well then that's how Black people are.

Brittney, an African American second-year student, shared an experience from a class in which a conversation focused on affirmative action and the way in which a White student categorized the use of affirmative action on college admissions:

A White girl in one of my classes was saying how affirmative action and things like that, that lower the admissions standards, lower the prestige of the university. And when we were talking about it in class, it was hard for her to accept that it's not all about just me being Black.

Student participants consistently questioned the institution's commitment to them as compared to the institution's commitment to White students. Not only do African American students experience the consequences of stereotypes, but the participants of this study spoke openly about feeling valued only for their potential to contribute to the entertainment and education of White students. Through these experiences, African American students perceived no reason to feel that Southern State University is committed to them.

\section{Student Perception of Potential of Campus Community}

Data from this study did not reveal any indications of participants experiencing a campus-wide community. The data did not indicate that there is an absence of a campus-wide community, but what came out of analysis was that African Americans in this study felt relegated to and remained at the margins. The feelings of marginalization can be interpreted as participants being called into the larger campus-wide community, but only at the beck and call of members of the dominant group.

LaFonda, an African American third-year student and a member of an African American sorority, illustrated this issue in a conversation about homecoming:

The homecoming concert is one way they try to relate to African Americans on campus. They'll bring in an African American artist that we kind of sort of know, and a White artist that we sort of know. But it's like, if something goes wrong involving the [African American] artist, especially with how it's portrayed in the media, they say that's why we shouldn't invite them [African American artists] in the first place.

Whitney, an African American second-year student, had experiences in discussions with White students about the stereotype of students of color being 
unable to be admitted to Southern State University under the same admissions standards to which White students are held:

The assumption is that [African Americans] get in because there are lower admissions rules for standardized tests, like we aren't capable of scoring high on the ACT. And I'm like, I got a 28 on the ACT, for your information. And White students will say how we only get certain scholarships that are set aside for African American students, but I'm like, I took some of your scholarships, too.

The potential of campus community lies in enclaves and clusters of African American students. Bringing all these clusters and splintered groups together with the "central" community to develop some new shared community, in which differences are valued rather than a reason to separate, is essential for a college to have an inclusive campus culture. Until then, a PWI will remain a White campus culture that finds inclusion for Other only where there is pre-existing overlap between the cultures rather than welcoming difference.

\section{Student Use of Proactive Social Adjustment Strategies}

Upon arriving at Southern State University, Kenny, an African American fourthyear student, shared that he had a number of bad experiences with White students, some of whom he had known and been friendly with in high school, but as he progressed in his classes and his major, the nature of his interactions began to change:

When I first came in, I used to hang with the Black engineering society, but now I hang with all the engineers. But I did that because when I got down here, I had bad experiences with White people; they were mean, so I would stay away from them. But after taking classes with them, you just get to know people, so now I hang with them. But at the same time, there are just a few [African American students] in engineering.

Kenny's experience of becoming involved in a student organization structured around a particular interest, or in Kenny's case, an academic program, is a sign of a proactive effort to become integrated into the campus community. It is possible that, through his initial involvement in the Black engineering society, Kenny was able to discover comfort zones at Southern State University. Kenny might have benefited from this involvement early in his time at the institution in that it helped him learn to negotiate the various formal and informal structures of Southern State University.

\section{Student Investment in Social Interactions}

Janelle, an African American third-year student, shared her perceptions of transitioning from a high school that she described as "50/50 Black and White." 
Janelle had expected Southern State University to be significantly different from her high school, where separate African American and White proms continue each year. When the homecoming court is announced during football season, Janelle describes that there are two courts: one African American and one White. When the winners are announced during half-time of the homecoming game, there are two sets: an African American queen and king and a White queen and king, but as Janelle arrived at State, issues of race did not seem terribly different from what she was hoping to leave behind from high school. She sees a number of involvement opportunities stratified by race, and in her second semester decided to pledge an African American sorority.

Alicia, a Black fourth-year student commented:

I think the university is good about claiming or giving lip service to the fact that they want diversity, but then when you see organizations that do recruitment and they're supposed to work with retention or whatever, and like 12 blonde White females, 12 blonde White males, and everybody's in business and has on suits. But there's nothing diverse about the people who are trying to recruit me.

Alicia's perception of student organizations highlights that African American students have to put extra effort forth in becoming involved on campus. Her comments not only highlight the difficulty of becoming involved in the main aspects of campus life through formal organizations, but that African American students' opportunities for involvement rest in minority-based activities.

\section{Student Perception of Institutional Integrity}

Data from the current study suggest that African American students do not perceive institutional integrity on the part of Southern State University. A key component linked to a concept of institutional integrity is the perception of differing standards and differential treatment at Southern State University: one set that is the norm of the institution for Whites and another inferior set for students of color. Ashlei, an African American fourth-year student, used Greekletter organizations as an example in illustrating the differing standards that exist at Southern State:

There are two different standards on campus. Like, last summer there was a big drug problem that had come to light in one of the White fraternity houses, and someone died, and that fraternity is still going strong. And when that guy died, the university talked about what a loss this was to the university. But if that had happened in one of the Black fraternities, that frat would be gone.

Ashlei's account of the incidents at the White fraternity house was covered by the student newspaper in the summer of 2006. The front page story highlighted the loss of the student as an outstanding member of the State family who would be missed. Details of the severity of the events that had been ongoing in the house were buried deep inside the paper. 


\section{Implications for Practice}

There are several important implications for practitioners at Southern State University, and institutions like it, to consider. Most of them are not groundbreaking; however, they continue to paint an ever more detailed and defined picture with which many who work with student development issues are aware. Even though students in this study showed a desire to succeed in spite of the difficulties in front of them, this spirit is not one that institutions should find desirable or encouraging. Instead, the fact that students needed to find this motivation in order to succeed is troubling. In order to create a more supportive environment, institutions should consider some important steps.

Institutions of higher education must first and foremost seek to offer a clear and consistent message and environment for all students, rather than one that makes students feel marginalized or that the university is acting in a duplicitous manner. The importance of environment for African American students at PWIs has been clearly established (Harper \& Quaye, 2007; Museus \& Quaye, 2009). For students to find an inconsistently applied set of rules that seems to perpetually value the dominant culture, while exacting higher standards from minority students, defeats or cripples efforts to develop a welcoming environment where students can grow.

The inclusion of African American students in the campus discourse seems to not only have an influence on their persistence and retention, or even their perception of the environment around them. Instead, inclusion impacts their identity development, and student affairs practitioners and administrators alike need to be highly cognizant of this and plan accordingly. Harper and Quaye (2007) suggested that students' perceptions of social disadvantage caused many African American students to seek participation in at least some mainstream organizations, although it was through Black student organizations that African American male students found their greatest engagement. Students who negotiate the PWI environment in this way may reach the highest of Cross's (1995) development levels, internalization, in which the student feels part of both Black and White cultures without feeling like he or she is neglecting or having to leave either behind.

\section{Conclusion}

This study has shown that African American students who persist from year to year at a PWI in the south do so through a type of social interaction. The social structures of the institution are steeped in Whiteness, as the dominance of Whiteness extends far beyond the structural diversity of the student population and into the values, norms, and mores of its social structures. African American students who do persist utilize a variety of mechanisms to cope with the discrimination and racism that they face at the institution, which infiltrate every aspect of their lives.

The findings of this qualitative research study suggest that, for the participants 
in the study, the assumptions made by Braxton et al. (2004) regarding persistence of African American students do not necessarily hold true. Despite this, the model proposed by Braxton et al. (2004) offers a significant starting point to understanding the intricacies of the experiences of African American students and other students of color as those experiences relate to persistence decisions. African American students at Southern State University experience limited social integration within the institution as a whole, although those who do persist experience high levels of integration within a variety of enclaves of African American subcultures at the institution.

It is the authors' hope that this study fills a void in scholarship toward understanding the persistence of African American students in higher education, particularly those who enroll in PWIs. Through continued research, we must continually work to fill the void, as it will continue to exist as long as the departure of African American students from institutions of higher learning continues. The findings of this study support the primary reason for developing models that seek to explain African American student persistence: a wholesale rejection of assimilation. The participants of this study certainly cannot be said to be assimilating into the culture of Whiteness that is Southern State University.

This study does have limitations. The experiences of students at Southern State University, particularly of the participants, might not be able to be generalized to African American students at other PWIs, even of similar size and mission. The relatively low number of participants is also a potential limitation of this study; however, what this approach does offer is a means to better understand the experiences of students of color at a PWI and what those experiences can mean to students' persistence decisions. These limitations can be addressed through further research by expanding the number of sites of study, increasing the number of participants, and utilizing mixed methods approaches to explore the phenomena associated with the persistence of African American students at PWIs.

Overall, the findings of the current study offer support for most of the suppositions put forth by Braxton et al. (2004) as important elements to consider in understanding students' persistence decisions; however, the social integration experienced by study participants comes to bear in racially divided enclaves and clusters. Bean (2005) and Tinto (2006) have postulated an even more sweeping vision of external factors that affect the internal socialization process, and this too needs to be part of the integration question going forward. What this study highlights is how institutional processes can and do impact individual persistence and that they do so in a way that supports the suppositions of Braxton et al. (2004). 
Bean, J. P. (2005). Nine themes of college student retention. In A. Seidman (Ed.), College student retention: Formula for success (pp. 215-243). Westport, CT: Praeger Publishers.

Berger, J. B., \& Milem, J. F. (1999). The role of student involvement and perceptions of integration in a causal model of student persistence. Research in Higher Education, 40(6), 641-664.

Bloor, M., Frankland, J., Thomas, M., \& Robson, K. (2001). Focus groups in social research. London, England: Sage Publications.

Braxton, J. M. (Ed.) (2000). Reworking the student departure puzzle. Nashville, Tennessee: Vanderbilt University Press.

Braxton, J. M., Hirschy, A. S., \& McClendon, S. A. (2004). Understanding and reducing college student departure. ASHE-ERIC Higher Education Report, 30(3). San Francisco: Jossey-Bass.

Braxton, J. M., Sullivan, A. S., \& Johnson, R. (1997). Appraising Tinto's theory of college student departure. In J. Smart (Ed.), Higher Education: Handbook of Theory and Research (Vol. 12, pp. 107-164). New York: Agathon.

Cabrera, A. F., Castaneda, M. B., Nora, A., \& Hengstler, D. (1992). The convergence between two theories of college persistence. Journal of Higher Education, 63(2), 143-164.

Cabrera, A. F., Nora, A., Terenzini, P. T., Pascarella, E., \& Hagedorn, L. S. (1999). Campus racial climate and the adjustment of students to college: A comparison between White and African-American students. Journal of Higher Education, 70(2), 134-160.

Cross, W. E., Jr. (1995). The psychology of Nigrescence: Revising the Cross model. In J. G. Ponterotto, J. M. Casas, L. A. Suzuki, \& C. M. Alexander (Eds.), Handbook of multicultural counseling, pp. 93-122. Thousand Oaks, CA: Sage.

Flowers, L. A. (2004). Retaining African-American students in higher education: An integrative review. Journal of College Student Retention, 6(1), 23-35.

Geertz, C. (1973). The Interpretation of Cultures. New York: Basic Books.

Guiffrida, D. A. (2006). Toward a cultural advancement of Tinto's theory. Review of Higher Education, 29(4), 451-472.

Harper, S. R., \& Quaye, S. J. (2007). Student organizations as venues for Black identity expression and development among African American male student leaders. Journal of College Student Development, 48(2), 127-144.

Holmes, S. L., Ebbers, L. H., Robinson, D. C., \& Mugenda, A. G. (2000). Validating African American students at predominantly White institutions. Journal of College Student Retention, 2(1), 41-56.

Laird, T. F. N., Bridges, B. K., Morelon-Quainoo, C.L., Williams, J. M., \& Holmes, M. S. (2007). African American and Hispanic student engagement at minority serving and predominantly White institutions. Journal of College Student Development, 48(1), 39-56.

Lewis, A. E., Chesler, M., \& Forman, T. A. (2000). The impact of "colorblind" ideologies on students of color: Intergroup relations at a predominantly White university. Journal of Negro Education, 69(1-2), 74-91. 
Levin, S., Van Laar, C., \& Foote, W. (2006). Ethnic segregation and perceived discrimination in college: Mutual influences and effects on social and academic life. Journal of Applied Social Psychology, 36(6), 1471-1501.

Loo, C. M., \& Rolison, G. (1986). Alienation of ethnic minority students at a predominantly White university. Journal of Higher Education, 57(1), 58-77.

Morgan, D. L. (1997). Focus groups as qualitative research, 2nd edition. Thousand Oaks, California: Sage Publications.

Museus, S. D., \& Quaye, S. J. (2009). Toward an intercultural perspective of racial and ethnic minority college student persistence. The Review of Higher Education, $33(1), 67-94$.

Nora, A., \& Cabrera, A. F. (1996). The role of perception of prejudice and discrimination on the adjustment of minority students to college. Journal of Higher Education, 67(2), 119-148.

Pascarella, E. T., \& Terenzini, P. T. (1991). How college affects students: Findings and insights from twenty years of research. San Francisco: Jossey-Bass.

Pascarella, E.T., \& Terenzini, P.T. (2005). How college affects students (Vol. 2): A third decade of research. San Francisco: Jossey-Bass.

Person, D. R., \& Christensen, M. C. (1996). Understanding Black student culture and Black student retention. NASPA Journal, 34(1), 47-56.

Rendon, L. I., Jalomo, R. E. , Nora, A. (2000). Theoretical considerations in the study of minority student retention in higher education. In J. M. Braxton (Ed.), Reworking the student departure puzzle (pp. 127-156). Nashville, Tennessee: Vanderbilt University Press.

Smith, D. G., \& Wolf-Wendel, L. E. (2005). The challenge of diversity: Involvement or alienation in the academy? (2nd ed.). ASHE Higher Education Report, 31(1). San Francisco: Jossey-Bass.

Spady, W. G. (1971). Dropouts from higher education: Toward an empirical model. Interchange, 2, 38-62.

Stewart, D. W., Shamdasani, P. N., \& Rook, D. W. (2007). Focus groups: Theory and practice, 2nd edition. Thousand Oaks, California: Sage Publications.

Strauss, A., \& Corbin, J. (1998). Basics of qualitative research: Techniques and procedures for developing grounded theory, (2nd ed.). Thousand Oaks, CA: Sage Publications.

Strayhorn, T. L. (2008). The invisible man: Factors affecting the retention of low-income African American males. National Association of Student Affairs Professionals (NASAP) Journal, 11 (1), 66-87.

Swail, W. S., Redd, K. E., \& Perna, L. W. (2003). Retaining minority students in higher education. ASHE-ERIC Higher Education Report, 30(2).

Tierney, W. G. (1992). An anthropological analysis of student participation in college. Journal of Higher Education, 63(6), 603-618.

Tierney, W. G. (2000). Power, identity, and the dilemma of college student departure. In J. M. Braxton (Ed.), Reworking the student departure puzzle (pp. 213-234). Nashville, TN: Vanderbilt University Press.

Tinto, V. (1975). Dropout from higher education. Review of Educational Research, $45,89-125$. 
Tinto, V. (1987). Leaving college: Rethinking the causes and cures of student attrition (1st ed.). Chicago: University of Chicago Press.

Tinto, V. (1993). Leaving college: Rethinking the causes and cures of student attrition (2nd ed.). Chicago: University of Chicago Press.

Tinto, V. (2006). Research and practice of student retention: What's next? Journal of College Student Retention: Research, Theory and Practice, 8(1), 1-19. 